Bull. Chem. Soc. Ethiop. 2019, 33(1), 1-10.

ISSN 1011-3924

(c) 2019 Chemical Society of Ethiopia and The Authors

Printed in Ethiopia

DOI: https://dx.doi.org/10.4314/bcse.v33i1.1

\title{
DETERMINATION OF MALATHION BY HOMOGENEOUS LIQUID-LIQUID MICRO EXTRACTION VIA FLOTATION ASSISTANCE COMBINED WITH GAS CHROMATOGRAPHY IN WATER SAMPLES
}

\author{
Mohammad Rezaee ${ }^{*}$ Kamal Saberyan and Parisa Tajer-Mohammad-Ghazvini \\ Materials and Nuclear Fuel Research School, Nuclear Science and Technology Research \\ Institute, Atomic Energy Organization of Iran, P.O. Box 14395-836, Tehran, Iran
}

(Received June 25, 2018; Revised November 21, 2018; Accepted December 9, 2018)

\begin{abstract}
A new preconcentration method termed, homogeneous liquid-liquid microextraction via flotation assistance (HLLME-FA) has been developed for the sensitive determination of Malathion in water samples. In this method, home-designed extraction cell was used for facile collection of organic solvent during the extraction procedure. The novel approach avoids the centrifugation step. In this extraction method, a mixture of toluene (extraction solvent) and acetone (homogeneous solvent) was added into a special vessel after addition of the sample solution. By using air flotation, the organic solvent was collected at the conical part of the designed cell. Parameters affecting the extraction efficiency such as type and volume of extraction and homogeneous solvents, ionic strength and extraction time were studied and optimized. The new method (HLLME-FA) provides detection limit of $0.1 \mu \mathrm{g} \mathrm{L}{ }^{-1}$ and calibration graph was linear in the range of $1.0-200 \mu \mathrm{g} \mathrm{L}^{-1}$. The results show that HLLMEFA is a suitable method for the determination of Malathion in water samples.
\end{abstract}

KEY WORDS: Homogeneous liquid-liquid microextraction, Flotation assistance, Malathion, Gas chromatography, Water samples

\section{INTRODUCTION}

Malathion as organophosphorous insecticide was used for the control of insects on fruits and vegetables. Also, Malathion has been used to control mosquitoes, flies, miscellaneous household insects, animal parasites, and human head and body lice [1]. The partition coefficient, $\log \mathrm{P}$ of Malathion is 2.89 and the structure of Malathion is shown in the Figure 1.

Figure 1. Structure of Malathion.<smiles>CCOC(=O)CC(SP(C)(=S)OC)C(=O)OCC</smiles>

The use of pesticides provides benefits for increasing agricultural production, but by bioaccumulation through the food web they can eventually become a risk or threat to both animals and humans. OPPs can be treated in a wide range of surface water, fruit, vegetable and food stuff [2].

For fast monitoring of the cause of environmental contamination by OPPs and accomplishment of risk assessment, sensitive, rapid and simple analytical methods are required. Several studies have been reported on the analysis of OPPs pesticides in aqueous sample [3-9]. Pesticide samples are usually enriched by liquid-liquid extraction[10, 11] or solid-phase extraction $[12,13]$. In view of the aqueous sample, the conventional liquid-liquid extraction (LLE) often needs large amounts of toxic solvent and time-consuming procedure. Solid-phase extraction (SPE) is a less time consuming than LLE and is used in many environmental fields

*Corresponding author. E-mail: chem.rezaee219@gmail.com

This work is licensed under the Creative Commons Attribution 4.0 International License 
[14]. However, the SPE column needs pretreatment and requires toxic organic solvent for the elution step.

Solid-phase microextraction (SPME) has been developed for pretreatment of OPPs [15-17]. It is solvent-free, fast, portable and easy to use. But SPME also suffers from some drawbacks: its fiber is fragile and has limited lifetime and the sample carry-over is also a problem.

The solvent microextraction technique such as dispersive liquid-liquid microextraction (DLLME) [18-23] which overcomes these problems by reducing the amount of the organic solvent have been used to extract and determination of OPPs pesticides [24]. Extraction solvents often used in DLLME are chlorobenzene, carbon tetrachloride and chloroform with higher density than water and all of which are potentially toxic to human and the environment. Typically, most DLLME method needs a centrifugation step in order to sediment extraction solvent. It is noted that the numbers of organic solvents lighter than water are more than heavier solvents.

AbdelatyHabila et al. used activated carbon for separation of Malathion from soil and water samples [25]. The limit of detection (LOD) was $0.026 \mathrm{ng} \mathrm{L}^{-1}$. In 2018, a novel and green deep eutectic solvent based liquid phase microextraction (DES-LPME) methodology has been proposed for the assessment of Rhodamine B from cosmetic products and water samples. A deep eutectic solvent (DES) consist of tetrabutylammoniumchloride-decanoic acid (1:2) as extraction solvent and tetrahydrofuran as emulsification agent were used for the microextraction of Rhodamine B [26].

In 2012, a novel microextraction technique named homogeneous liquid-liquid microextraction via flotation assistance (HLLME-FA) was developed by Haji Hosseini and coworkers [27]. HLLME-FA has been applied for the analysis of different compounds such as polycyclic aromatic hydrocarbons [28], uranium [29], chlorobenzenes [30], deltamethrin and permethrin [31], myclobutanil [32], cadmium and copper [33] and thiobencarb [34] in different real samples.

The aim of this work is to develop an analytical method with suitable detection limits and good precision for the determination of Malathion. Extraction of the analyte took place from sample into the fine droplets of the extraction solvent. The extracting organic phase was separated by air flotation and the upper phase was withdrawn for gas chromatography analysis. The effects of various parameters, such as the kind and volume of the extraction and homogeneous solvents, extraction time and ionic strength were studied. The efficiency of the presented method was tested by analyzing real samples.

\section{EXPERIMENTAL}

\section{Chemicals and reagents}

Malathion (98\% purity) was purchased from Merck (Frankfurter Strasse, Darmstadt, Germany). Stock standard solution of Malathion was prepared in methanol $(\geq 99.9 \%)$. Working standard solutions were prepared in doubly distilled water. All these solutions were stored at $4{ }^{\circ} \mathrm{C}$ in the absence of light. n-Hexane ( $\geq 96 \%)$, n-heptane ( $\geq 99 \%)$, toluene ( $\geq 99.9 \%)$, 1-octanol $(\geq 99 \%)$, methanol $(\geq 99.9 \%)$, acetone $(\geq 99.8 \%)$, acetonitrile $(\geq 99.9 \%)$ and sodium chloride $(\geq 99.5 \%)$ were purchased from Merck (Frankfurter Strasse, Darmstadt, Germany). The used water was purified on a Youngling ultra-pure water purification system (Aqua $\mathrm{Max}^{\mathrm{TM}}$-ultra, Dongan-gu, Anyang-si, Gyeonggi-do,Korea) (99.99\%). All the used reagents were of analytical grade or of the highest purity available.

\section{Instrumentation}

Analysis was carried out on a gas chromatograph (Agilent GC-7890) (Santa Clara, California, United States) equipped with a split/splitless injector system and flame ionization detector at 
$270{ }^{\circ} \mathrm{C}$. A capillary column (DB5, $25 \mathrm{~m} \times 0.32 \mathrm{~mm}$ i.d. and $0.25 \mu \mathrm{m}$ film thickness) from SGE (Victoria, Australia) was used for the separation. The column oven temperature was initially heldat $150{ }^{\circ} \mathrm{C}$ for $2 \mathrm{~min}$, raised to $200{ }^{\circ} \mathrm{C}$ at $5{ }^{\circ} \mathrm{C} \mathrm{min}^{-1}$ and held for $5 \mathrm{~min}$. The injector temperature was set at $250{ }^{\circ} \mathrm{C}$. The carrier gas was helium (purity, 99.999\%) at a flow rate of 2 $\mathrm{mL} \min ^{-1}$.

\section{HLLME-FA procedure}

A mixture of $0.5 \mathrm{~mL}$ acetone $(\geq 99.8 \%$, Frankfurter Strasse, Darmstadt, Germany) (homogeneous solvent) and $50 \mu \mathrm{L}$ toluene (extraction solvent) were added to the home-designed extraction cell (length $=40 \mathrm{~cm}$; diameter $=1.5 \mathrm{~cm})$.

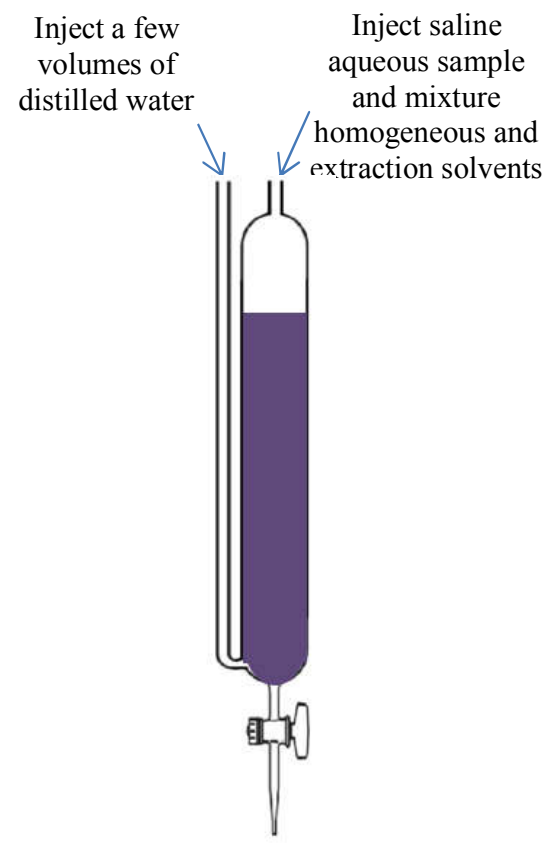

Figure 2. Schematic of home-designed extraction cell.

A $22 \mathrm{~mL}$ of saline aqueous sample solution was injected into extraction vessel. In this step, an emulsion consisting of the fine droplets of the extraction solvent were formed. After about 5 min, by using air flotation, the organic solvent was collected on the top of the solution. Then, elevating the level of organic phase and its transformation to the narrow portion of the extraction vessel was done by injecting a few volumes of distilled water through the glass tube on the side of the cell. The collected phase in the narrow section of vessel was removed for injecting into the GC-FID system. The schematic of home-designed extraction cell is demonstrated in Figure 2.

\section{RESULTS AND DISCUSSION}

In order to obtain the best extraction performance, different parameters affecting the extraction process such as the kind and volume of extraction and homogeneous solvents, salt amount, and 
extraction time were studied and optimized. Optimization of the variables mentioned was performed using one variable at a time method.

Selection of extraction solvent

In HLLME-FA, to facilitate collection of the extraction solvent in the narrow section of the extraction cell, the extraction solvent must have a lower density than water. Aliphatic solvents such as n-heptane, n-hexane, have virtually no toxic effects to mammals or birds. The U.S. Environmental Protection Agency states that aliphatic hydrocarbons present no major concerns for terrestrial effects. Aliphatic hydrocarbons are not as toxic as aromatic compounds. Information gained from animal studies supports the observations in humans that toluene can be ototoxic. Ototoxicity has been observed in rats when toluene was injected subcutaneously, via gavage dosing or by inhalation. Moderately toxic when ingested or inhaled, slightly hazardous when absorbed through skin, mild chronic irritant and chronic hazards are moderate by all routes.1-octanol very hazardous in case of ingestion by humans. Acute oral toxicity (LD50) of 1 -octanol is $1790 \mathrm{mg} / \mathrm{kg}$ in mouse. Four organic solvents including 1-octanol, n-hexane, nheptane and toluene were evaluated. The extraction recoveries for 1-octanol, n-hexane, nheptane and toluene were 57, 36, 28 and $71 \%$, respectively. Therefore, toluene possessed the highest extraction recovery compared to the other extraction solvents. It seems that the solubility of Malathion in the toluene is more than the other tested solvents. Thus, toluene was chosen as the extraction solvent for the subsequent experiments.

\section{Selection of homogeneous solvent}

Miscibility of homogeneous solvent in the extraction solvent and aqueous phase is the main point for selection of a homogeneous solvent. Acetone, acetonitrile and methanol were examined as homogeneous solvents. The extraction recoveries for acetone, acetonitrile and methanol were 71,69 and $70 \%$, respectively. Therefore, the recovery variations using different homogeneous solvents were not remarkable. Thus, acetone was chosen as the homogeneous solvent for subsequent experiments, because of low cost and toxicity.

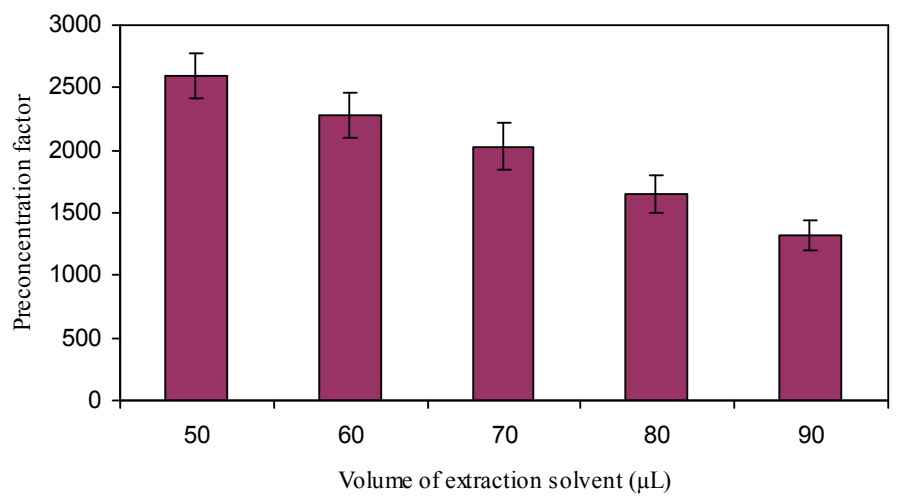

Figure 3. Effect of volume of extraction solvent on the preconcentration factor $(n=3)$.

Selection of extraction and homogeneous solvent volumes

Optimization of volumes of the extracting solvent and the homogeneous solvent is a further step in development of a HLLME-FA procedure. Both of these volumes can influence extraction efficiency of the proposed method and thus have to be optimized. In order to study the effect of 
extraction solvent volume on the extraction efficiency, different volumes of toluene $(50.0,60.0$, $70.0,80.0$, and $90.0 \mu \mathrm{L}$ ) were tested. By increasing the volume of toluene, preconcentration factor of the analyte decreased, owing to the increase in the volume of the collected organic solvent and dilution effect. Based on the experimental results (Figure 3), $50.0 \mu \mathrm{L}$ toluene was adopted for further experiments.

For obtaining optimized volume of acetone, experiment was done using different volumes of acetone $(0.5,1.0,1.5$ and $2.0 \mathrm{~mL})$. The results (Figure 4) showed that with increasing of homogeneous solvent volume (acetone), the extraction efficiency decreased. This observation could be attributed to the increasing lipophilic characteristic in aqueous sample solution and decreasing distribution constant. Therefore, $0.5 \mathrm{~mL}$ of acetone was selected as the optimum volume for the homogeneous solvent.

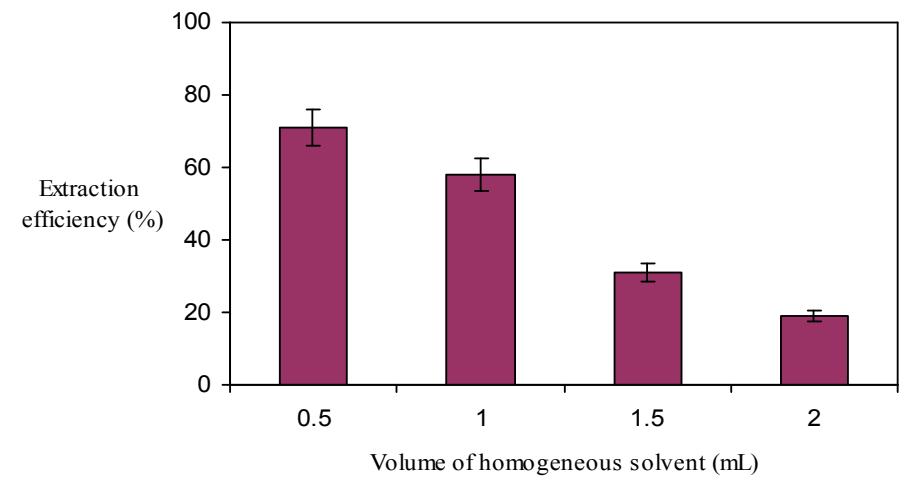

Figure 4. Effect of volume of homogeneous solvent on the extraction efficiency $(n=3)$.

\section{Effect of salt addition}

For investigating the influence of the salt addition on the HLLME-FA performance, several experiments were performed by adding varying the concentration of $\mathrm{NaCl}$, from 0.5 to $3 \mathrm{M}$ (Figure 5). By increasing the $\mathrm{NaCl}$ concentration up to $1.5 \mathrm{M}$, the extraction efficiency of the analyte increases, because of salting-out effect. Higher salt concentration decreases extraction efficiency, because of increasing solution viscosity that reduces dispersion phenomenon Therefore, $1.5 \mathrm{M}$ was used in further experiments.

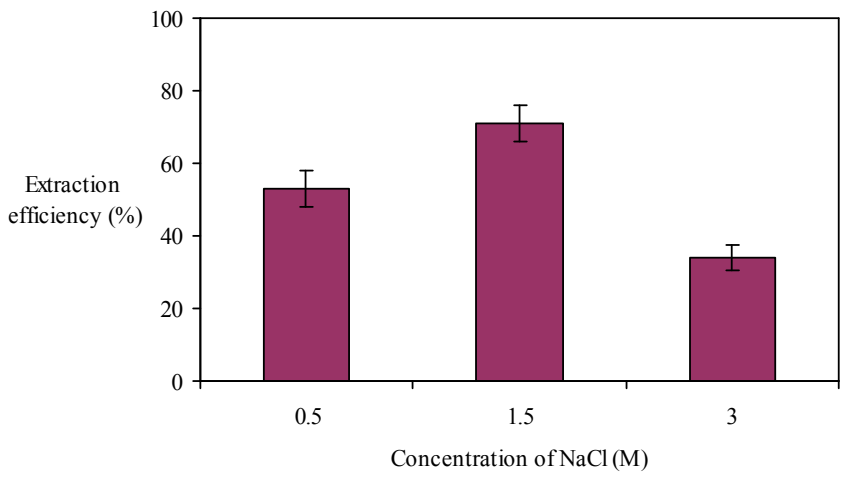

Figure 5. Effect of $\mathrm{NaCl}$ concentration on the extraction efficiency $(\mathrm{n}=3)$.

Bull. Chem. Soc. Ethiop. 2019, 33(1) 


\section{Effect of extraction time}

In HLLME-FA, extraction time is defined as interval between beginning of the dispersion and the end of dispersion just before air flotation. According to the other literature [27-33], extraction time is an important factor that may affect the analyte extraction efficiency from aqueous phase into the organic phase. Thus, the variation in extraction efficiency of Malathion as a function of extraction time was studied in the range of $0.5-10 \mathrm{~min}$. The extraction recoveries in the extraction time of $0.5,1,5$ and $10 \mathrm{~min}$ were $61,71,70$ and $69 \%$, respectively. Therefore, the time of $1 \mathrm{~min}$ is a good selection for extraction time. More than $1 \mathrm{~min}$, the recoveries are constant.

\section{Quantitative analysis}

The characteristics of calibration curve were obtained under optimized conditions (Table 1). Linearity was observed in the range of 1.0 to $200 \mu \mathrm{g} \mathrm{L}^{-1}$ for Malathion with coefficients of determination $\left(\mathrm{r}^{2}\right)$ of 0.9988 . Calibration curve was plotted between peak area and concentrations of Malathion. The relative standard deviation (RSD, $n=4)$ at the three different concentration levels of Malathion are shown in Table 2. The detection limit (LOD) of an individual analytical procedure is the lowest amount of analyte in a sample which can be detected. LOD was calculated based on signal-to-noise approach. Determination of the signalto-noise ratio is performed by comparing measured signals from samples with known low concentrations of analyte with those of blank samples and by establishing the minimum concentration at which the analyte can be reliably detected. A signal-to-noise ratio of 3 is generally considered acceptable for estimating the detection limit. The limit of detection (LOD), based on signal-to-noise ratio $(\mathrm{S} / \mathrm{N})$ of 3 was $0.1 \mu \mathrm{g} \mathrm{L}^{-1}$. The limit of quantitation (LOQ), based on signal-to-noise ratio $(\mathrm{S} / \mathrm{N})$ of 10 was $1.0 \mu \mathrm{g} \mathrm{L}^{-1}$.

Table 1. Quantitative results of HLLME-FA and GC-FID method for Malathion. Extraction conditions: homogeneous solvent (acetone) volume, $0.5 \mathrm{~mL}$; extraction solvent (toluene) volume, $50.0 \mu \mathrm{L}$; concentration of $\mathrm{NaCl}, 1.5 \mathrm{M}$; extraction time, $1 \mathrm{~min}$.

\begin{tabular}{|c|c|c|c|c|}
\hline Analyte & Linear range $\left(\mu \mathrm{g} \mathrm{L}^{-1}\right)$ & $\mathrm{LOD}^{\mathrm{a}}\left(\mu \mathrm{g} \mathrm{L}^{-1}\right)$ & $\mathrm{LOQ}^{\mathrm{b}}\left(\mu \mathrm{g} \mathrm{L}^{-1}\right)$ & $\mathrm{r}^{2 \mathrm{c}}$ \\
\hline Malathion & $1.0-200$ & 0.1 & 1.0 & 0.9988 \\
\hline
\end{tabular}
$\mathrm{LOD}$, limit of detection for signal/noise $=3 .{ }^{\mathrm{b}} \mathrm{LOQ}$, limit of quantitation for signal/noise $=10 .{ }^{\mathrm{c}}$ coefficientof
determination.

Table 2. Relative standard deviation (RSD) $(\%)(n=4)$ at three concentration levels of Malathion.

\begin{tabular}{|c|c|}
\hline Concentration of Malathion $\left(\mu \mathrm{g} \mathrm{L}^{-1}\right)$ & RSD (\%) \\
\hline 5 & 7.8 \\
\hline 10 & 6.2 \\
\hline 100 & 4.5 \\
\hline
\end{tabular}

A comparison between the proposed method and the other methods for the extraction of Malathion are presented in Table 3. The RSD\% and extraction time needed for the proposed method is better than of both single drop microextraction (SDME) [35] and solid-phase microextraction (SPME) [36] methods. Also, the disadvantages of SDME method are fast stirring which may break up the organic solvent drop; air bubble formation is possible and it is time-consuming and in most cases equilibrium is not obtained even after a long time. SPME suffers from some drawbacks: its fiber is fragile and has limited lifetime and desorption temperature, and also sample carry-over is a problem. The quantitative results of the proposed work are comparable with SDME and SPME methods without using sensitive detector such as MS and NPD. The important drawback of DLLME [24] is that the extraction solvent is limited to solvents of density higher than water in order to be sedimented by centrifugation. These 
solvents are typically chlorinated solvents such as chlorobenzene, chloroform and carbon tetrachloride, all of which are potentially toxic to human and environment. Typically, most DLLME method has a centrifugation step, which is the extra time-consuming step in the extraction. Therefore, the main advantages of the proposed method are the novel method does not need centrifugation to separate the organic phase and it is possible to the usage of lowdensity extraction solvents.

Table 3. Comparison of the proposed method with other extraction methods for determination of the Malathion in water samples.

\begin{tabular}{|c|c|c|c|c|c|}
\hline Methods & RSD \% & $\begin{array}{c}\text { Dynamic linear } \\
\text { range }\left(\mu \mathrm{g} \mathrm{L}^{-1}\right)\end{array}$ & $\begin{array}{c}\text { Limit of detection } \\
\left(\mu \mathrm{g} \mathrm{L}^{-1}\right)\end{array}$ & $\begin{array}{c}\text { Extraction time } \\
(\mathrm{min})\end{array}$ & Ref. \\
\hline SDME-GC-MS & 14 & $0.5-100$ & 0.073 & 15 & {$[35]$} \\
\hline DLLME -GC-FPD & 4.7 & $0.02-100$ & 0.008 & 3 & {$[24]$} \\
\hline SPME-GC-NPD & 17 & $0.1-10$ & 0.04 & 60 & {$[36]$} \\
\hline HLLME-FA-GC-FID & 7.8 & $1.0-200$ & 0.1 & 1 & This work \\
\hline
\end{tabular}

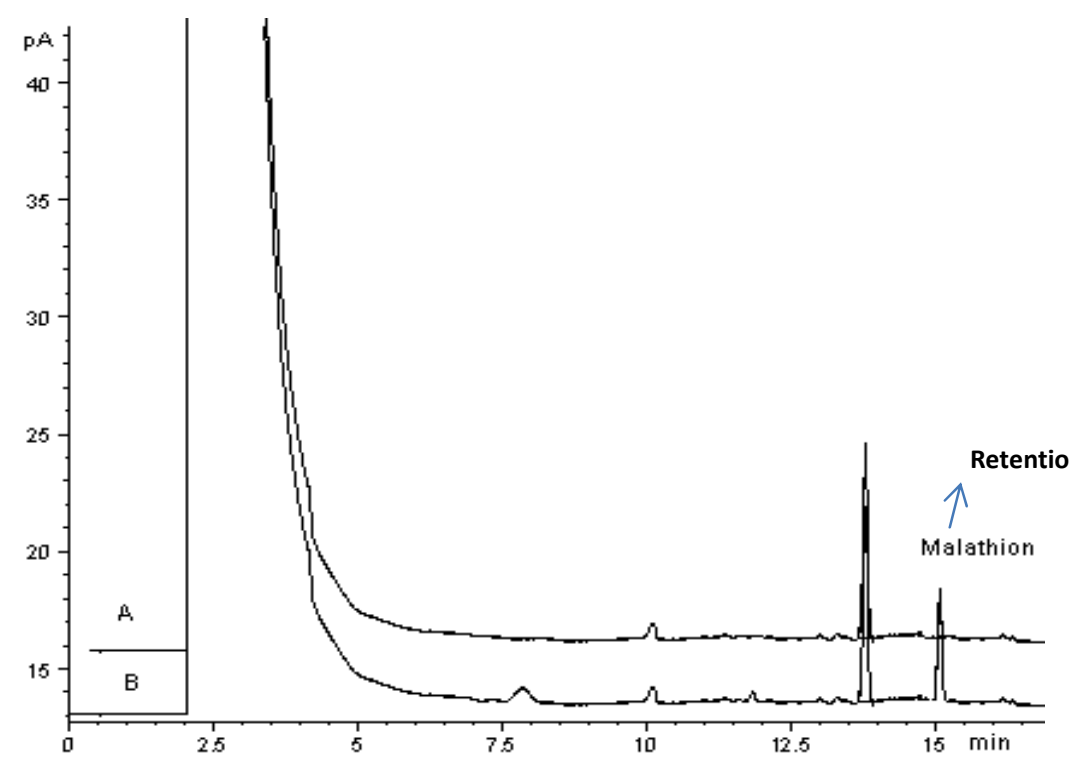

Figure 6. GC-FID chromatograms of Malathionin river water, before spiking (A) and after spiking with $5.0 \mu \mathrm{g} \mathrm{L}^{-1}$ of Malathion(B) using proposed method combined with GCFID under optimum conditions ( $\mathrm{GC}$ conditions: the column oven was initially held at $150{ }^{\circ} \mathrm{C}$ for $2 \mathrm{~min}$, raised to $200{ }^{\circ} \mathrm{C}$ at $5{ }^{\circ} \mathrm{C} \mathrm{min}{ }^{-1}$ and held for $5 \mathrm{~min}$. The injector temperature was set at $250{ }^{\circ} \mathrm{C}$ and flame ionization detector at $270{ }^{\circ} \mathrm{C}$. The carrier gas was helium at a flow rate of $2 \mathrm{~mL} \mathrm{~min}^{-1}$ ).

Real water analysis

The proposed analytical method was applied to determine Malathion in three types of water samples. Recovery experiments were performed at spiked concentration level of $5 \mu \mathrm{g} \mathrm{L}^{-1}$ by adding the standard solution into the water samples. For each sample, the extraction was repeated three times. Relative recoveries and relative standard deviations were calculated and listed in Table 4. The results indicated that the samples were free of Malathion. The relative recovery $(\mathrm{RR})$ is obtained from the following equation:

Bull. Chem. Soc. Ethiop. 2019, 33(1) 


$$
\mathrm{RR} \%=C_{\text {found }}-C_{\text {real }} / C_{\text {added }} \times 100
$$

where $C_{\text {found }}, C_{\text {real }}$ and $C_{\text {added }}$ are the concentrations of the analyte after the addition of a known amount of standard in a real sample, the concentration of the analyte in a real sample and the concentration of a known amount of standard, which was spiked to the real sample, respectively. As can be seen, recoveries were in the range of $92-98 \%$ in the spiked samples indicating that the real water matrices had little effect on the extraction efficiency, and the method could be used for the determination of Malathion in the water samples. Figure 6 shows typical chromatograms of the river water before and after spiked at the concentration level of $5 \mu \mathrm{g} \mathrm{L^{-1 }}$ after HLLME-FA. It is mentioned that the peak $(13.75 \mathrm{~min})$ is related to unknown compound which is present in river water.

Table 4. Determination of the relative recoveries of Malathion in spiked tap, well and river water samples.

\begin{tabular}{|l|c|c|c|c|}
\hline Sample & $\begin{array}{c}\text { Concentration of } \\
\text { Malathion }\left(\mu \mathrm{g} \mathrm{L}^{-1}\right)\end{array}$ & $\begin{array}{c}\text { Added Malathion } \\
\left(\mu \mathrm{g} \mathrm{L}^{-1}\right)\end{array}$ & $\begin{array}{c}\text { Found Malathion } \\
\left(\mu \mathrm{g} \mathrm{L}^{-1}\right) \pm \mathrm{RSD}, \mathrm{n}=3\end{array}$ & Recovery (\%) \\
\hline Tap water $^{\mathrm{a}}$ & n.d $\mathrm{d}^{\mathrm{d}}$ & 5.0 & $4.9 \pm 6.8$ & 98 \\
\hline Well water $^{\mathrm{b}}$ & n.d. & 5.0 & $4.7 \pm 8.4$ & 94 \\
\hline River water $^{\mathrm{c}}$ & n.d. & 5.0 & $4.6 \pm 10.2$ & 92 \\
\hline
\end{tabular}

${ }^{\mathrm{a}}$ From drinking water system of Tehran, Iran. ${ }^{\mathrm{b}}$ The water was collected from well in Tehran, Iran. ${ }^{\mathrm{c}}$ Kolakchal river water, Tehran, Iran. ${ }^{\mathrm{N}}$ Not detected.

\section{CONCLUSION}

In this study, HLLME-FA method was successfully used for the preconcentration of Malathion from water samples prior to analysis by GC-FID. Home-designed extraction cell was used for the easy collection of the floated organic solvent on the surface of aqueous sample.Under optimized working conditions,preconcentration factor up to 2500 was obtained from the targetedanalyte allowing to reach the LODof $0.1 \mu \mathrm{g} \mathrm{L}^{-1}$ with an acceptable precision. The analytical technology offers numerous advantages such as ease of operation, low detection limit and relatively short analysis time. The performance of this procedure in the Malathion extraction from three different water samples was excellent. As a conclusion, the proposed method possesses great potential in the analysis of trace Malathion in water samples.

\section{ACKNOWLEDGEMENT}

Financial support by Nuclear Science and Technology Research Institute, Atomic Energy Organization of Iran (Tehran, Iran) for the support during the period of this research is gratefully acknowledged.

\section{REFERENCES}

1. Hayes, W.J. Organic Phosphorus Pesticides in Pesticides Studied in Man, Williams and Wilkins: Baltimore; 1982; pp 333-340.

2. Driss, M.R.; Hennion, M.C.; Bouquerra, M.L. Determination of carbaryl and some organophosphorus pesticides in drinking water using on-line liquid chromatographic preconcentration techniques. J. Chromatogr. A 1993, 639, 352-358.

3. Johnson, W.E.; Fendinger, N.J.; Pilmmer, J. R. Solid-phase extraction of pesticides from water: Possible interferences from dissolved organic material. Anal. Chem. 1991, 63, 15101513.

4. Eisert, R.; Levsen, K.;Wunsch, G. Element-selective detection of pesticides by gas chromatography-atomic emission detection and solid-phase microextraction. J. Chromatogr. A 1994, 683, 175-183.

5. Eisert, R.; Levsen, K. Determination of organophosphorus triazines and 2,6-dinitroaniline pesticides in aqueous samples via solid-phase microextraction (SPME) and gas 
chromatography with nitrogen-phosphorus detection. Fresenius J. Anal. Chem. 1995, 351, 555-562.

6. Boyd-Boaland, A.; Magdic, S.; Pawliszyn, J. Simultaneous determination 60 pesticides in water using solid-phase microextraction and gas chromatography-mass spectrometry. Analyst 1996, 121, 929-938.

7. Sng, M.T.; Lee, F.K.; Lakso, H.A. Solid-phase microextraction of organophosphorus pesticides from water. J. Chromatogr. A 1997, 759, 225-230.

8. Valor, I.; Molto, J.C.; Apraiz, D.; Font, G. Matrix effects on solid-phase microextraction of organophosphorus pesticides from water. J. Chromatogr. A 1997, 767, 195-203.

9. Gorecki, T.; Mindrup, R.; Pawliszyn, J. Pesticides by solid-phase microextraction, results of a round robin test. Analyst 1996, 121, 1381-1386.

10. Barcelo, D.; Porte, C.; Cid, D.; Albaines, J. Detemination of organophsphorus compounds in Mediterranean coastal waters and biota samples using gas chromatography with nitrogenphosphorus and chemical ionization mass spectrometric detection. Int. J. Environ. Anal. Chem. 1990, 38, 199-209.

11. Bellar, T.A.; Budde, W.L. Determination of nonvolatile organic compounds in aqueous environmental samples using liquid chromatography/mass spectrometry. Anal. Chem. 1998, 60, 2076-2083.

12. Marvin, C.H.; Brindle, I.D.; Hall, C.D.; Chiba, M. Development of an automated highperformance liquid chromatographic method for the on-line preconcentration and determination of trace concentrations of pesticides in drinking water. J. Chromatogr. A 1990, 503, 167-176.

13. Carabias Martinez, R.; Rodriguez-Gonzalo, E.; Amigo Moran, M.J.; Hernandez Mendez, J. Sensitive method for the determination of organophosphorus pesticides in fruits and surface wáter by high performance liquid chromatography with ultraviolet detection. J. Chromatogr. A 1992, 607, 37-45.

14. Fillion, J.; Sauve, F.; Selwyn, J. Multiresidue method for the determination of residues of 251 pesticides in fruits and vegetables by gas chromatography/mass spectrometry and liquid chromatography with fluorescence detection. J. AOAC Int. 2000, 83, 698-713.

15. Yao, Z.W.;Jiang, G.B.;Liu, J.M.;Cheng, W. Application of solid-phase microextraction for the determination of organophosphorous pesticides in aqueous samples by gas chromatography with flame photometric detector. Talanta 2001,55, 807-814.

16. Su, P.G.; Huang, S.D. Determination of organophosphorus pesticides in water by solidphase microextraction. Talanta 1999, 49, 393-402.

17. Helena, P.; Locita, I.K. Solid-phase microextraction. Trends Anal. Chem. 1999, 18, 272-282.

18. Rezaee, M.; Assadi, Y.; Milani Hosseini, M.R.;Aghaee, E.; Ahmadi, F.; Berijani, S. Determination of organic compounds in water using dispersive liquid-liquid microextraction. J. Chromatogr. A 2006, 1116, 1-9.

19. Rezaee, M.; Yamini, Y.; Faraji, M.Evolution of dispersive liquid-liquid microextraction. $J$. Chromatogr. A 2010, 1217, 2342-2357.

20. Rezaee, M.; Khalilian, F. Preconcentration of uranium in water samples using dispersive liquid-liquid micro-extraction coupled with solid-phase extraction and determination with inductively coupled plasma-optical emission spectrometry. Bull. Chem. Soc. Ethiop. 2015, 29, 367-376.

21. Mohammadi, S.Z.; Shamspur, T.; Baghelani, Y.M. Combination of flame atomic absorption spectrometry with ligandless-dispersive liquid- liquid microextraction for preconcentration and determination of trace amount of lead in water samples. Bull. Chem. Soc. Ethiop. 2013, 27, 161-168.

22. Mashayekhi, H.A.; Abroomand-Azar, P.; Saber-Tehrani, M.; Waqif, S.H. Rapid and sensitive determination of biphenyl and biphenyl oxide in water samples using dispersive 
liquid-liquid microextraction followed by gas chromatography. Int. J. Environ. Anal. Chem. 2011, 91, 516-524.

23. Bahramifar, N.; Rahnama, R.; Saberimoghaddam, S. Trace determination of bisphenol-A in landfill leachate samples by dispersive liquid-liquid microextraction followed by high performance liquid chromatography. Bull. Chem. Soc. Ethiop. 2014, 28, 329-338.

24. Berijani, S.; Assadi, Y.; Anbia, M.; Milani Hosseini, M.R.; Aghaee, E. Dispersive liquidliquid microextraction combined with gas chromatography-flame photometric detection: Very simple, rapid and sensitive method for the determination of organophosphorus pesticides in water. J. Chromatogr. A 2006, 1123, 1-9.

25. Abdelaty Habila, M.; Abdullah AL Othman, Z.; A. Al-Tamrah, S.; Abdel Ghafar, A.; Soylak, M. Activated carbon from waste as an efficient adsorbent for Malathion for detection and removal purposes. J. Ind. Eng. Chem. 2015, 32, 336-344.

26. Yilmaz, E.; Soylak, M. A novel and simple deep eutectic solvent based liquid phase microextraction method for Rhodamine B in cosmetic products and water samples prior to its spectrophotometric determination. Spectrochim. Acta A Mol. Biomol. Spectrosc. 2018, 202, 81-86.

27. Haji Hosseini, M.; Rezaee, M.; Mashayekhi, H.A.; Akbarian, S.; Mizani, F.; Pourjavid, M.R. Determination of polycyclic aromatic hydrocarbons in soil samples using flotation assisted homogeneous liquid-liquid microextraction. J. Chromatogr. A 2012, 1265, 52-56.

28. Haji Hosseini, M.; Rezaee, M.; Akbarian, S.; Mizani, F.; Pourjavid, M.R.; Arabieh, M. Homogeneous liquid-liquid microextraction via flotation assistance for rapid and efficient determination of polycyclic aromatic hydrocarbons in water samples. Anal. Chim. Acta 2013, 762, 54-60.

29. Rezaee, M.; Khalilian, F. Determination of uranium in water samples using homogeneous liquid-liquid microextraction via flotation assistance and inductively coupled plasma-optical emission spectrometry. J. Radioanal. Nucl. Chem. 2015, 304, 1193-1200.

30. Khalilian, F.; Rezaee, M. Development of a sensitive methodology for the analysis of chlorobenzenes in water samples by combination of homogeneous liquid-liquid microextraction via flotation assistance and gas chromatography-flame ionization detection. J. Chin. Chem. Soc. 2014, 61, 1351-1356.

31. Haddai, H.; Shirani, M.; Semnani, A.; Rezaee, M.; Mashayekhi, H.A.; Hosseinian, A. Simultaneous determination of deltamethrin and permethrin in water samples using homogeneous liquid-liquid microextraction via flotation assistance and GC-FID. Chromatographia 2014, 77, 715-721.

32. Shirani, M.; Akbar, A.; Hassani, M.; Goli, A.; Habibollahi, S.; Akbarian, P. Homogeneous liquid-liquid microextraction via flotation assistance coupled with gas chromatography-mass spectrometry for determination of myclobutanil in cucumber, tomato, grape, and strawberry using genetic algorithm. Int. J. Environ. Anal. Chem. 2018, 98, 271-285

33. Baroumand, N.; Akbari, A.; Shirani, M.;Shokri, Z. Homogeneous liquid-liquid microextraction via flotation assistance with thiol group chelating reagents for rapid and efficient determination of cadmium(II) and copper(II) ions in water samples. Water Air Soil Pollut. 2015, 226, 2254-2259.

34. Mashayekhi, H.A. Determination of thiobencarb in water samples by gas chromatography using a homogeneous liquid-liquid microextraction via flotation assistance procedure. Bull. Chem. Soc. Ethiop. 2013, 27, 359-366.

35. Lambropoulou, D.A.; Psillakis, E.; Albanis, T.A.; Kalogerakis, N. Single-drop microextraction for the analysis of organophosphorous insecticides in water. Anal. Chim. Acta 2004, 516, 205-211.

36. Beltran, J.; Lopez, F.J.; Cepria, O.; Hernandez, F. Solid-phase microextraction for quantitative analysis of organophosphorus pesticides in environmental water samples. $J$. Chromatogr. A 1998, 808, 257-263. 